Article

\title{
A Simple Yet Effective Preanalytical Strategy Enabling the Application of Aptamer-Conjugated Gold Nanoparticles for the Colorimetric Detection of Antibiotic Residues in Raw Milk
}

\author{
Víctor Díaz-García *(i), Braulio Contreras-Trigo, Camila Rodríguez, Pablo Coelho $\mathbb{( \mathbb { B } )}$ and Patricio Oyarzún *(i)
}

Citation: Díaz-García, V.;

Contreras-Trigo, B.; Rodríguez, C.;

Coelho, P.; Oyarzún, P. A Simple Yet Effective Preanalytical Strategy Enabling the Application of Aptamer-Conjugated Gold Nanoparticles for the Colorimetric Detection of Antibiotic Residues in Raw Milk. Sensors 2022, 22, 1281. https://doi.org/10.3390/s22031281 Academic Editors: Maria Lepore and Ines Delfino

Received: 5 December 2021 Accepted: 29 December 2021 Published: 8 February 2022

Publisher's Note: MDPI stays neutral with regard to jurisdictional claims in published maps and institutional affiliations.

Copyright: (C) 2022 by the authors. Licensee MDPI, Basel, Switzerland. This article is an open access article distributed under the terms and conditions of the Creative Commons Attribution (CC BY) license (https:// creativecommons.org/licenses/by/ $4.0 /$ )
Facultad de Ingeniería y Tecnología, Universidad San Sebastián, Sede Concepción, Concepción 4080871, Chile; bcontrerast@docente.uss.cl (B.C.-T.); rodriguezcamila@gmail.com (C.R.); pablo.coelho@uss.cl (P.C.)

* Correspondence: victor.diazg@uss.cl (V.D.-G.); patricio.oyarzun@uss.cl (P.O.)

\begin{abstract}
The misuse of antibiotics in the cattle sector can lead to milk contamination, with concomitant effects on the dairy industry and human health. Biosensors can be applied in this field; however, the influence of the milk matrix on their activity has been poorly studied in light of the preanalytical process. Herein, aptamer-conjugated gold nanoparticles (nanoaptasensors) were investigated for the colorimetric detection in raw milk of four antibiotics used in cattle. The effect of milk components on the colorimetric response of the nanoaptasensors was analyzed by following the selective aggregation of the nanoparticles, using the absorption ratio $A_{520} / A_{720}$. A preanalytical strategy was developed to apply the nanoaptasensors to antibiotic-contaminated raw milk samples, which involves a clarification step with Carrez reagents followed by the removal of cations through dilution, chelation (EDTA) or precipitation $\left(\mathrm{NaHCO}_{3}\right)$. The colorimetric signals were detected in spiked samples at concentrations of antibiotics as low as 0.25 -fold the maximum residue limits (MRLs) for kanamycin $(37.5 \mu \mathrm{g} / \mathrm{L})$, oxytetracycline $(25 \mu \mathrm{g} / \mathrm{L})$, sulfadimethoxine $(6.25 \mu \mathrm{g} / \mathrm{L})$ and ampicillin $(1 \mu \mathrm{g} / \mathrm{L})$, according to European and Chilean legislation. Overall, we conclude that this methodology holds potential for the semiquantitative analysis of antibiotic residues in raw milk obtained directly from dairy farms.
\end{abstract}

Keywords: nanoaptasensor; preanalytical processing; clarification; antibiotics; gold nanoparticles; aptamer

\section{Introduction}

Bovine milk is one of the most important nutrient-rich food sources in the human diet [1], the global production of which reached 540,925 million tons in July 2021 [2]. The quality and safety of milk and dairy products are of paramount importance for the food industry and public health [3]. There is a rising concern surrounding the presence of antibiotic residues in raw milk, which are extensively used in dairy farms for the treatment and prevention of bacterial diseases affecting cattle as well as to improve animal performance [4]. Exposure to low levels of antibiotics in milk and milk derivatives is known to cause serious harmful effects in human health [5]. In addition, the usage of antibiotics in food-producing animals is a well-recognized factor in triggering the emergence of antimicrobial resistance, which contributes to select bacterial strains and antimicrobial resistance genes that can be further transferred to the human microbiome [6]. Bacterial multidrug resistance to antibiotics is today among the biggest threats to global health, accounting for over 700,000 deaths each year due to infections caused by antibiotic-resistant bacteria (ARB) [7]. ARB are expected to cause 10 million deaths per year by 2050 at an economic cost of USD 100 trillion [8]. Finally, antibiotic-contaminated raw milk may interfere with fermentation processes of dairy products by inhibiting the growth of lactic acid bacteria (starter cultures) [9].

The Codex Alimentarius Commission develops international food standards, including reference maximum residue limits (MRLs) for veterinary drugs. In the European 
Union (EU) the MRLs of antibiotic residues in milk are fixed by Commission Regulation $\mathrm{N}^{\circ} 37 / 2010$ [10], which are comparable to those set in Chilean legislation [11]. The Ministry of Health in Chile implements a national plan to control the presence of antibiotic residues in dairy products, while the Agriculture and Livestock Service (SAG, for its acronym in Spanish) is responsible for ensuring the sanitary inspection and control of veterinary pharmaceuticals in dairy cattle farms. Accordingly, raw milk contaminated with antibiotic residues at levels above the MRLs must be discarded to prevent them from entering the human food chain and their impacts on food safety and public health. Therefore, rapid screening kits (e.g., SNAPR beta-lactam tests) to monitor the presence of antibiotic residues in bovine raw milk have become a major requirement for farmers and the dairy industry. However, these tests are qualitative and unsuitable for the simultaneous detection of multiple groups of antibiotics. There is thus growing scientific and industrial interest in supporting the development of fast, sensitive and quantitative biosensing technologies to determine antibiotic residues in raw milk [12].

Nanotechnology is currently driving innovation in a pleyade of fields, including the sensing of environmental and food contaminants, industrial advanced materials and nanocatalysis applications in the chemical industry, as well as for water purification and the detection of explosives, among others [13-17]. Nanobiosensors are nanoscale sensors that include a biological recognition molecule (bioreceptor), which allow for improved analytical performances along with rapid and sensitive detection of analytes in the ppb $(\mu \mathrm{g} / \mathrm{L})$ concentration range $[18,19]$. A promising class of bioreceptors is DNA aptamers, which consist of short single-stranded oligonucleotides that provide high affinity and specificity for non-nucleotide molecules, including those with low molecular weight, toxic or nonimmunogenic [20]. The combination of AuNPs with aptamers in nanoaptasensors (NAS) is widely used to investigate the detection of a variety of analytes [21-24], with a growing number of reports addressing the detection of antibiotics in the field of food safety $[25,26]$. Surface plasmon resonance (SPR) is an optical property of AuNPs that allows the development of label-free NAS capable of analyzing multiple analytes in real time [27]. SPR causes a sharp and intense absorption band in the visible range, enabling colorimetric detection by following a red-to-purple-blue shift of the absorption spectrum during the aggregation of the nanoparticles. Optical NAS are a preferred sensing technique due to their non-invasive nature, high sensitivity, direct readout and easy coupling with other technologies, with recent developments in optical technology lowering the cost of the instrumentation $[28,29]$. However, most works address colorimetric detection exclusively from the point of view of the analytical behavior of the biosensor. Consequently, significant gaps remain in the literature regarding the preanalytical processes that are required to implement this technology in real-world applications with complex matrices.

Milk is a heterogeneous fluid composed of multi-dispersed phases of emulsion (fatwater), colloidal suspension (protein-water) and solution (salts-water), whose chemical complexity interferes with the analysis of antibiotic residues [30]. Previous reports shed light on the capacity of AuNP-based colorimetric aptasensors to detect a few of the antibiotic residues in commercial milk, including kanamycin [31], tetracycline [32], oxytetracycline [33] and streptomycin [34,35]. Preanalytical techniques described in these studies are often laborious and involve the use of chemical agents such as ethyl acetate, trichloroacetic acid or trifluoracetic acid. In addition, solvent extraction is especially challenging for nanobiosensor technology since $\mathrm{pH}$ and ionic environment severely influence their analytical behavior [36].

Herein, we investigated the effects of the main raw milk components on the activity of aptamer-conjugated AuNPs in the colorimetric detection of antibiotics belonging to four different groups used in cattle: kanamycin (aminoglycosides), oxytetracycline (tetracyclines), sulfadimethoxine (sulfonamides) and ampicillin (beta-lactams). A methodology was proposed to address preanalytical and analytical variables affecting the colorimetric detection of the four antibiotics in this matrix. The utility of this strategy was demonstrated 
according to the MRLs of veterinary drugs in food for human consumption accepted in EU and Chilean legislation.

\section{Materials and Methods}

\subsection{Chemicals and Reagents}

Kanamycin, oxytetracycline, sulfadimethoxine, ampicillin, tetrachloroauric acid solution $\left(\mathrm{HAuCl}_{4} \cdot 3 \mathrm{H}_{2} \mathrm{O}\right)$, Carrez clarification reagent kit, Total Protein Kit, Micro Lowry reagent kit and Sephadex G-25 resin were purchased from Merk (Darmstadt, Germany). Ethyl acetate, lactose, ethylenediaminetetraacetic acid (EDTA), sodium citrate and all salt solutions were purchased from Winkler (Santiago, Chile). Aptamers were purchased from Integrated DNA Technologies, Inc. (Coralville, IA, USA).

\subsection{Synthesis of Gold Nanoparticles (AuNPs)}

The synthesis of AuNPs was carried out according to the standard citrate reduction method [24]. Briefly, $100 \mathrm{~mL}$ of $1 \mathrm{mM}$ tetrachloroauric acid solution $\left(\mathrm{HAuCl}_{4} \cdot 3 \mathrm{H}_{2} \mathrm{O}\right)$ was prepared with nanopure water $(18 \mathrm{M} \Omega \cdot \mathrm{cm})$. The solution was isovolumetrically heated to boiling point under stirring and refluxed with a three-neck round flask connected to the condenser. Then, $10 \mathrm{~mL}$ of $38.8 \mathrm{mM}$ trisodium citrate solution at $\mathrm{pH} 11$ was preheated to $60{ }^{\circ} \mathrm{C}$ and quickly added to the boiling solution of $\mathrm{HAuCl}_{4}$ under vigorous stirring [35]. After the color of the solution turned deep red the mixture was refluxed for an additional $30 \mathrm{~min}$ and cooled down to room temperature without stirring for $2 \mathrm{~h}$. The resulting nanoparticle suspension was filtered with Millipore nylon filters $(0.45 \mu \mathrm{m})$ and preserved in the dark at $4^{\circ} \mathrm{C}$. The concentrations of AuNPs and NAS were calculated according to the Beer-Lambert law by measuring the absorbance at $520 \mathrm{~nm}$ (extinction coefficient of $\left.2.01 \times 10^{8} \mathrm{M}^{-1} \mathrm{~cm}^{-1}\right)[37,38]$.

\subsection{AuNPs Characterization}

The spectroscopic characterization of the synthesized AuNPs was carried out with an Epoch $^{\mathrm{TM}}$ microplate spectrophotometer (Biotek Instruments, Winooski, VT, USA). The size distribution and surface charge characterization (pZ) of the AuNPs were determined with a Zetasizer Nano-ZS90 dynamic light scattering (DLS) analyzer (Malvern Instruments, Westboroug, MA, USA). The characterization of the size and morphology of the nanoparticles was carried out by transmission electron microscopy (TEM) with a 4 Å resolution (TEM; JEOL-JEM 1200EX-II, Tokyo, Japan), using a Gatan CCD camera for image acquisition (model 782; Gatan, Inc., Pleasanton, CA, USA).

\subsection{Synthesis of NAS and the Determination of Detection Parameters}

AuNPs were functionalized with aptamers specific for the antibiotics listed in Table 1. Thiol-modified aptamers (C3-S-S-Aptamer) were reduced by incubation with dithiothreitol $0.1 \mathrm{M}$ in a phosphate buffer of $\mathrm{pH} 8$ for $3 \mathrm{~h}$ at $37^{\circ} \mathrm{C}$. Then, $3^{\prime}-\mathrm{SH}$-aptamers were purified by gel filtration with Sephadex G-25 and incubated with the AuNPs in a phosphate buffer $(10 \mathrm{mM}, \mathrm{pH} 7.4)$ for 2 days at room temperature and darkness [39]. AuNP-aptamer molar ratios of 1:20, 1:40 and 1:60 were investigated to determine the best parameters and conditions for the maximization of the colorimetric signal produced by the NAS in the detection of antibiotics at concentrations equal to their MRLs. The resulting NAS were activated by being heated at $80^{\circ} \mathrm{C}$ for $10 \mathrm{~min}$ and then cooled down at room temperature for $10 \mathrm{~min}$ to induce linear conformation on the nanoparticle surface. This step is paramount to stabilize the nanoparticles and to allow the aptamers to interact with the antibiotics. 
Table 1. Antibiotics used in the experiments, including their maximum acceptable levels in raw milk (MRLs) according to EU and Chilean legislation, and aptamers used in the NAS to recognize each antibiotic.

\begin{tabular}{|c|c|c|c|}
\hline Antibiotic & $\begin{array}{l}\text { Maximum Residual } \\
\text { Limit (MRL) }\end{array}$ & Aptamer Sequence (ssDNA) & Aptamer Ref. \\
\hline Kanamycin & $150 \mu \mathrm{g} / \mathrm{L}^{*}$ & $\begin{array}{c}5^{\prime} \text {-TGGGGGTTGAGGCTAAGCC } \\
\text { GA-3' (21b) }\end{array}$ & [40] \\
\hline Oxytetracycline & $100 \mu \mathrm{g} / \mathrm{L}$ * & $\begin{array}{l}\text { 5'-CGTACGGAATTCGCTAGCG } \\
\text { GGCGGGGGTGCTGGGGGAAT } \\
\text { GGAGTGCTGCGTGCTGCGGGG } \\
\text { ATCCGAGCTCCACGTG-3' (76b) }\end{array}$ & [41] \\
\hline Sulfadimethoxine & $\begin{array}{l}25 \mu \mathrm{g} / \mathrm{L}^{\dagger} \\
100 \mu \mathrm{g} / \mathrm{L}^{*}\end{array}$ & $\begin{array}{c}5^{\circ \prime} \text {-GAGGGCAACGAGTGTTTA } \\
\text { TAGA-3 }{ }^{\prime}(22 \mathrm{~b})\end{array}$ & [42] \\
\hline Ampicillin & $4 \mu \mathrm{g} / \mathrm{L}^{*, \dagger}$ & $\begin{array}{c}5^{\prime} \text {-GCGGGCGGTTGTATAGC } \\
\text { GG-3'(19b) }\end{array}$ & [43] \\
\hline
\end{tabular}

* EU legislation [10]. ${ }^{\dagger}$ Chilean legislation [11].

A typical assay in microplate wells consisted of $200 \mu \mathrm{L}$ of antibiotic solution incubated with $100 \mu \mathrm{L}$ of the activated NAS $(4 \mathrm{nM})$ at $60{ }^{\circ} \mathrm{C}$ for $10 \mathrm{~min}$, subsequently cooled down at room temperature. Then, $60 \mu \mathrm{L}$ of $\mathrm{NaCl} 1 \mathrm{M}$ was added into the solutions and incubated for $30 \mathrm{~min}$ to monitor the aggregation process. AuNP aggregation data were analyzed spectrophotometrically by measuring the shift of the plasmon resonance peak from $520 \mathrm{~nm}$ to $620 \mathrm{~nm}\left(\mathrm{~A}_{520} / \mathrm{A}_{620}\right)$. The absorbance values were calibrated by subtracting the value in nanopure water (blank) and expressed as the difference in colorimetric signal between the control (without antibiotic) and the antibiotic solution, using concentration ranges around their MRLs (Equation (1)):

$\frac{\mathrm{A} 520}{\mathrm{~A} 620}$ Control - Treatment $=$ Signal $\frac{\mathrm{A} 520}{\mathrm{~A} 620}$ NAS without antibiotics - Signal $\frac{\mathrm{A} 520}{\mathrm{~A} 620}$ NAS with antibiotics $($ MRL $)$

The aggregation of the NAS followed, during $60 \mathrm{~min}$ in a mixture of $100 \mu \mathrm{L}$ of the activated NAS and $200 \mu \mathrm{L}$ of nanopure water (without antibiotics). The absorbance was measured at $520 \mathrm{~nm}$ and $720 \mathrm{~nm}$ during $60 \mathrm{~min}$ (the absorption ratio $A_{520} / A_{720}$ ) upon the addition of the saline solution. Further experiments monitoring the SPR shift to $720 \mathrm{~nm}$ were also expressed according to Equation (1).

\subsection{Preanalytical Processing of Raw Milk}

Bulk tank raw milk samples $(50 \mathrm{~mL})$ were spiked with the antibiotics in final concentrations of $0.5 \times, 1 \times, 2 \times$ and $4 \times$ the corresponding MRLs and then homogenized for $30 \mathrm{~min}$. The samples were clarified by using both Carrez reagents and ethyl acetate as follows:

- Carrez clarification: Five hundred milliliters of Carrez I reagent was added into $10 \mathrm{~mL}$ of raw milk without antibiotics (control) or with kanamycin, oxytetracycline, sulfadimethoxine or ampicillin, and vortexed for $1 \mathrm{~min}$. Then, $500 \mathrm{~mL}$ of Carrez II reagent was added and vortexed for $1 \mathrm{~min}$ until the mixture was homogeneous, which was subsequently centrifuged at $1000 \times g$ for $5 \mathrm{~min}$. The supernatant (milk whey) was recovered and immediately used for the detection of antibiotics with the NAS.

- Ethyl acetate clarification: Four milliliters of raw milk was centrifuged for 20 min at 1000 and $10{ }^{\circ} \mathrm{C}$ to separate the fat. Then, $2 \mathrm{~mL}$ of the supernatant was diluted with $2 \mathrm{~mL}$ of nanopure water and stirred for $10 \mathrm{~min}$ in a vortex. Seven milliliters of ethyl acetate was added, vortexed for $15 \mathrm{~min}$ and centrifuged for $15 \mathrm{~min}$ at $1500 \times g$ and $4{ }^{\circ} \mathrm{C}$, which gave rise to a three-phase mixture. The bottom layer (milk whey) was recovered and centrifugated again before being stored at $4{ }^{\circ} \mathrm{C}$.

\subsection{Milk and Milk Whey Characterization}

The proximate analysis of raw milk and whey (by Carrez method) was determined in accordance with the standard methods of the Association of Official Analytical Chemists (AOAC methods) [44]: fat (AOAC 945.16), ash (AOAC 920.181), crude fiber (AOAC 962.09), total protein (total nitrogen $\times 6.25)($ AOAC 978.02), total carbohydrates (AOAC 929.09) and 
lactose (AOAC 982.14). The protein concentration was determined by the Lowry protein assay (Peterson's modification) with protein precipitation, using the Total Protein Kit, Micro Lowry, in accordance with the manufacturer's protocol. Optical density was measured at $650 \mathrm{~nm}$ in 96-well plates using and Epoch ${ }^{\mathrm{TM}}$ microplate spectrophotometer. The protein removal efficiency was determined according to Equation (2):

$$
\text { Protein removal efficiency }=\frac{C_{R M}-C_{M W}}{C_{R M}} \times 100
$$

where $C_{M W}$ is the protein concentration of the milk whey and $C_{R M}$ is the concentration of the raw milk.

\subsection{Colorimetric Detection of Antibiotics in Clarificatecd Raw Milk}

Ten milliliters of raw milk was spiked (contaminated) with kanamycin, oxytetracycline, sulfadimethoxine and ampicillin at final concentrations of $0.25 \times, 0.5 \times, 1 \times, 2 \times$ and $4 \times$ the MRL of each antibiotic and then incubated for $30 \mathrm{~min}$ at room temperature. The colorimetric detection of the antibiotics was thus investigated in solutions containing the main soluble components of bovine raw milk (lactose and ionic species) to determine their specific effect on the aggregation process of AuNPs (Table 2). Raw milk (with and without antibiotics) was clarified using the Carrez method, after which samples of the resulting whey were assessed with the NAS by following the aggregation according to the methodology described in Section 2.4 .

Table 2. Solutions employed to study the effect of soluble milk constituents on the aggregation of the NAS.

\begin{tabular}{|c|c|c|c|c|}
\hline Element & Concentration & $\begin{array}{l}\text { Synthetic } \\
\text { Milk Whey }\end{array}$ & $\begin{array}{l}\text { Lactose } \\
\text { Solution }\end{array}$ & Ionic Solution \\
\hline Lactose & $5 \% \mathrm{w} / \mathrm{v}$ & $X$ & $x$ & \\
\hline $\mathrm{Ca}^{2+}$ & $30.120 \mathrm{mM}(60.232 \mathrm{mEq} / \mathrm{L})$ & $X$ & & $X$ \\
\hline $\mathrm{Mg}^{2+}$ & $4.750 \mathrm{mM}(9.506 \mathrm{mEq} / \mathrm{L})$ & $X$ & & $X$ \\
\hline $\mathrm{Fe}^{3+}$ & $0.011 \mathrm{mM}(0.032 \mathrm{mEq} / \mathrm{L})$ & $X$ & & $X$ \\
\hline $\mathrm{PO}_{4}^{3-}$ & $30.582 \mathrm{mM}(91.745 \mathrm{mEq} / \mathrm{L})$ & $x$ & & $x$ \\
\hline $\mathrm{Na}^{+}$ & $23.587 \mathrm{mM}(23.587 \mathrm{mEq} / \mathrm{L})$ & $X$ & & $X$ \\
\hline $\mathrm{K}^{+}$ & $38,930 \mathrm{mM}(38.930 \mathrm{mEq} / \mathrm{L})$ & $X$ & & $X$ \\
\hline $\mathrm{Zn}^{2+}$ & $0.066 \mathrm{mM}(0.131 \mathrm{mEq} / \mathrm{L})$ & $X$ & & $X$ \\
\hline Citrate $^{3-}$ & $9.292 \mathrm{mM}(18.584 \mathrm{mEq} / \mathrm{L})$ & $X$ & & $x$ \\
\hline $\mathrm{Cu}^{2+}$ & $0.002 \mathrm{mM}(0.005 \mathrm{mEq} / \mathrm{L})$ & $X$ & & $X$ \\
\hline
\end{tabular}

The symbol $(\mathrm{X})$ indicates the presence of each particular milk component in the solutions.

\subsection{Colorimetric Detection of Antibiotics in Cation-Removed Milk Whey}

Raw milk samples were incubated with the antibiotics at concentrations of $0.25 \times$, $0.5 \times, 1 \times, 2 \times$ and $4 \times$ their MRLs and subsequently subjected to Carrez clarification (see Section 2.5). Prior to performing the experiments of antibiotics detection the whey samples $(1.5 \mathrm{~mL})$ were divided into three isovolumetric fractions to remove cations by different methods: (i) by adding $80 \mu \mathrm{L}$ of $\mathrm{NaHCO}_{3} 1 \mathrm{M}$ into the solutions to a final concentration of $30 \mathrm{mM}$, which were subsequently incubated $\left(10 \mathrm{~min}\right.$ at $\left.60^{\circ} \mathrm{C}\right)$, cooled down at room temperature and centrifugated at $20,000 \times g$ for $10 \mathrm{~min}$ to recover the supernatant; (ii) by adding $80 \mu \mathrm{L}$ of EDTA to a final concentration of $5 \mathrm{mM}$; and (iii) by diluting 1:1 with nanopure water to attenuate the effects of cations and lactose in the salt-induced aggregation of AuNPs. The absorbance values were normalized with respect to the absorbance ratio measured for the whey without antibiotics (control), according to the following equation:

$$
\text { Fold } \mathrm{A} 520 / \mathrm{A} 720=\frac{\operatorname{signal} \frac{\mathrm{A} 520}{\mathrm{~A} 720} \text { of NAS with antibiotic }}{\operatorname{signal} \frac{\mathrm{A} 520}{\mathrm{~A} 720} \text { of NAS without antibiotic }(\text { control })}
$$




\subsection{Statistical Analysis}

Data shown are the average \pm standard error of at least three independent experiments. Statistical significance was determined at a $95 \%$ confidence interval, using a nonparametric Mann-Whitney U test for the comparison of two groups.

\section{Results and Discussions}

\subsection{NAS and Detection Principle}

The NAS developed herein are based on previously reported aptamers specific to four antibiotics used in cattle (kanamycin, oxytetracycline, sulfadimethoxine and ampicillin). Numerous works in the nanobiosensor field are based on aptamers bound to the nanoparticles through electrostatic interactions, which is a suitable approach for the detection of antibiotics in a saline buffer solution or highly clarified matrices. The recognition of antibiotics by adsorbed aptamers causes them to detach from the AuNPs with the concomitant loss of stability and subsequent aggregation [41]. However, this strategy becomes less applicable in complex matrices containing chemical species that can interfere with the analytical method. Accordingly, the experimental approach followed in this work involved the covalent conjugation of the ssDNA aptamers on the AuNPs' surface (through thiol-gold interactions) to prevent their release from the nanoparticle surface. It is worth mentioning that this reaction has been well-characterized in numerous works, using different instrumental techniques such as X-ray photoelectron spectroscopy (XPS), X-ray diffraction (XRD) and atomic force microscopy (AFM). The resulting interaction between the thiol group and the gold surface is strong and stable, providing a robust mechanism to link aptamers onto AuNPs [45-48]. Importantly, the aptamers adopt a flexible random coil linear structure that allows their bases to interact with the nanoparticle surface through van der Waals forces [49]. Figure 1 provides a schematic description of the detection reaction, showing the aptamers coating the AuNPs' surface and inhibiting salt-induced aggregation due to electrostatic repulsions among the nanoparticles. However, in the presence of the antibiotics the aptamers adopt a folded structure that leads to a decrease in surface protection and the subsequent aggregation of the AuNPs upon the addition of $\mathrm{NaCl}$. The aggregation process is proportional to the antibiotic concentration and can be followed through the decrease in the absorption ratio $\left(\mathrm{A}_{520} / \mathrm{A}_{620}\right)$.
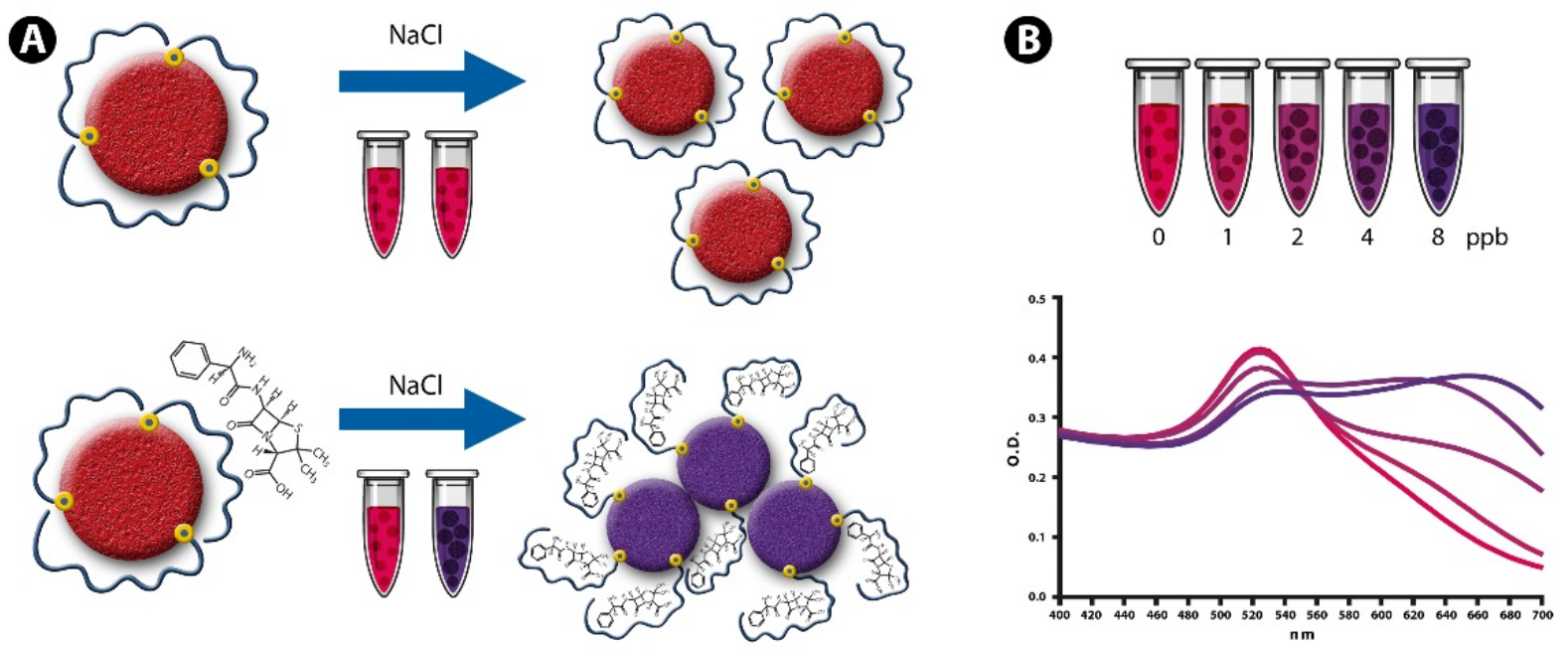

Figure 1. Schematic illustration showing the sensing principle of aptamer-conjugated AuNPs for the colorimetric detection of antibiotic residues present in raw milk. (A) Covalently conjugated aptamers in a random coiled linear structure inhibit salt-induced aggregation, while the conformational change induced by antibiotic interaction decreases surface protection and allows the aggregation of AuNPs upon the addition of $\mathrm{NaCl}$. (B) Absorption spectra of AuNPs showing antibiotic-induced aggregation of the nanoparticles and the resulting shift in the plasmon resonance peak (from red to blue-purple). 


\subsection{Determination of the Detection Parameters of NAS}

The detection parameters of (i) AuNP:aptamer molar ratio; (ii) absorption ratio; and (iii) incubation time were evaluated in water to select conditions that maximized the colorimetric signal generated by the NAS. AuNP:aptamer molar ratios of 1:20, 1:40 and 1:60 were compared for each NAS in the presence of each antibiotic at concentrations equal to the corresponding MRL in the EU (Table 1). In the case of sulfadimethoxine the MRL considered was $25 \mu \mathrm{g} / \mathrm{L}$ (instead of $100 \mu \mathrm{g} / \mathrm{L}$ ), which is the highest concentration of sulfonamides legally permitted in Chile for milk [11]. Differences in susceptibility to salt-induced aggregation at different molar ratios (AuNP functionalization) could be a consequence of the variable degrees of surface coverage in each NAS. Figure 2 shows the variation in the colorimetric signal produced by the NAS in detection of the four antibiotics upon the addition of $\mathrm{NaCl}$. Dispersed and aggregated NAS resulting from the detection process are presented in Figure 2, with TEM images (inset) showing typical spherical particles with diameters of $\sim 15 \mathrm{~nm}[24,27]$. The highest colorimetric response was determined in the case of kanamycin at a molar ratio of 1:60, while for oxytetracycline, sulfadimethoxine and ampicillin the best molar ratio was 1:20. These parameters were selected for subsequent antibiotic detection assays.

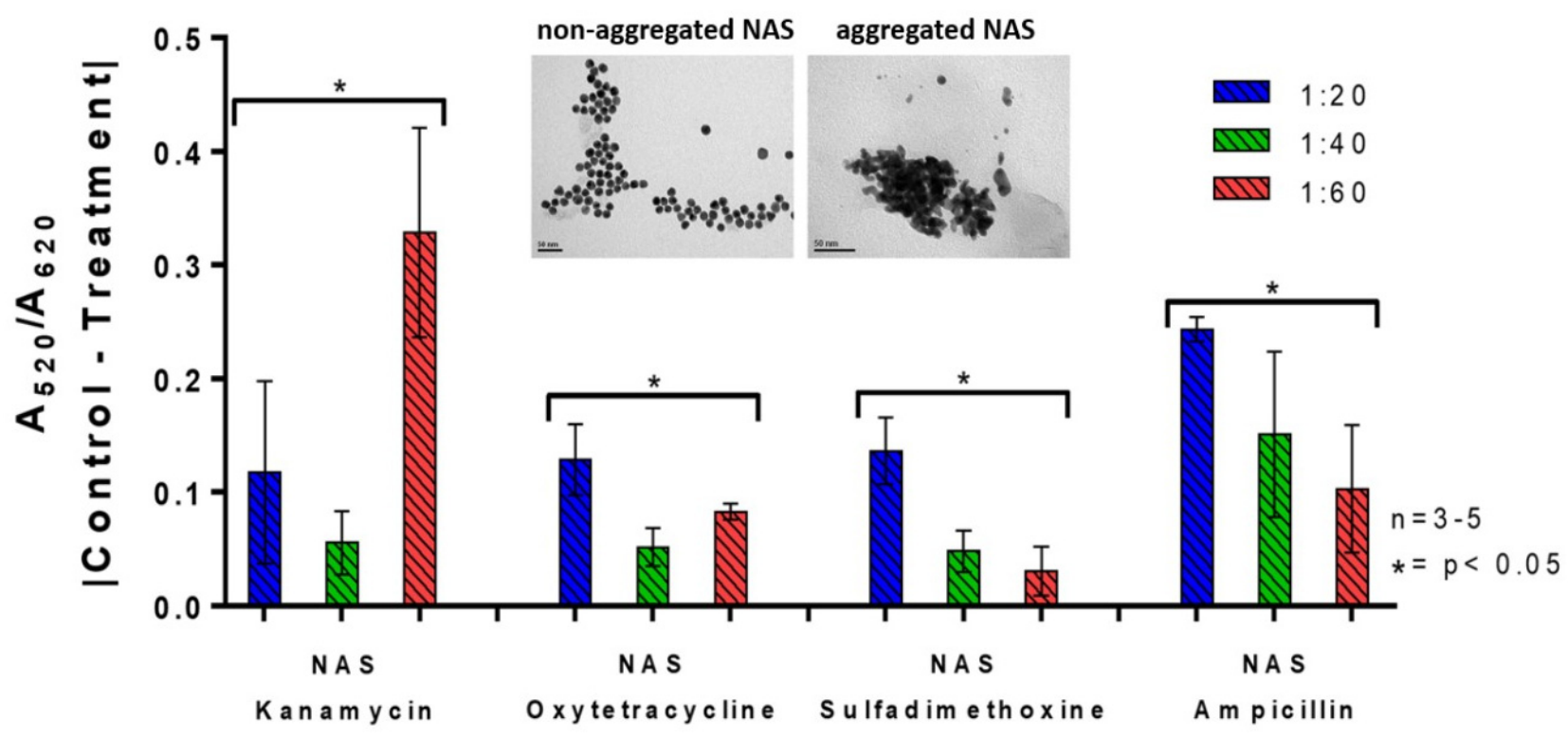

Figure 2. Colorimetric response of the NAS at molar ratios (AuNP:aptamer) of 1:20 (blue), 1:40 (green) and 1:60 (red) for the detection of antibiotics in water at their maximum concentration of residues permitted in milk (MRLs) for kanamycin, oxytetracycline, sulfadimethoxine and ampicillin. Treatments correspond to antibiotic-containing samples at the MRL concentrations and controls include nanopure water instead of antibiotics. The inset shows TEM images of dispersed NAS (before the detection of antibiotics) and aggregated NAS (after the detections of antibiotics). The absorbance readings were transformed according to Equation (1). Results were averaged from 3 to 5 independent experiments. Data were analyzed using a nonparametric Mann-Whitney U test. Asterisks denote statistically significant differences between the treatments and controls. ${ }^{*}=p<0.05$.

We hypothesized that differences in the colorimetric response of NAS at different molar ratios are associated with the effect of this parameter on the degree of surface coverage of the AuNPs by the aptamers (i.e., reactive surface). Thus, nanoparticles partially coated on their surface would have fewer reactive sites available to interact with the antibiotics in comparison with mostly coated nanoparticles. By calculating the surface coverages for each mol of NAS and considering the aptamer length for NAS-Kan (21b), NAS-Oxy (76b), NAS-Sul (22b) and NAS-Amp (19b), the total number of moles of DNA bases that would be interacting with each NAS is $1260 \mathrm{~b}$ (NAS-Kan), 1520b (NAS-Oxy), 440b (NAS-Sul) and 
380b (NAS-Amp) (Table S1). Interestingly, both NAS-Amp and NAS-Sul share a low total number of bases available on their surfaces and a lower concentration of antibiotics in the assays (MRLs of $4 \mu \mathrm{g} / \mathrm{L}$ and $25 \mu \mathrm{g} / \mathrm{L}$, respectively) in comparison with NAS-Oxy and NAS-Kan. By contrast, the latter groups of NAS have a higher number of bases coating the nanoparticle surface and a higher concentration of antibiotics $(100 \mu \mathrm{g} / \mathrm{L}$ and $150 \mu \mathrm{g} / \mathrm{L}$, respectively) in common. This analysis lends support to the relationship between reactive surface and the analyte concentration, given that NAS with a low proportion of aptamer coverage are more likely to become saturated at low concentrations and vice versa. Kim et al., for example, explored different molar ratios for the colorimetric detection of oxytetracycline in water, finding an optimal molar ratio of 1:50. However, this work was conducted with aptamers bound to AuNPs via electrostatic interactions, and the authors discussed the need to determine in each NAS the best molar ratio for optimal detection [35].

The shift of the SPR peak (from $520 \mathrm{~nm}$ ) associated with the aggregation of AuNPs spans a wide spectral region (until $800 \mathrm{~nm}$ ), despite most of the works in the field of NAS following the shift between $520 \mathrm{~nm}$ and 620 or $650 \mathrm{~nm}$ [50]. Accordingly, our group previously developed an electro-opto-mechanic device for high-resolution AuNP spectral data in a wavelength range from 400 to $800 \mathrm{~nm}$, which was proven to improve the analytical performance of NAS with the aid of machine learning tools [51]. With this in mind, AuNP aggregation data were analyzed spectrophotometrically between 400 and $750 \mathrm{~nm}$, using two absorption ratios $\left(A_{520} / A_{620}\right.$ and $\left.A_{520} / A_{720}\right)$ to select reading parameters that maximize the colorimetric signal associated with NAS detection and aggregation. As shown in Figure 3, the ratio $A_{520} / A_{720}$ outperformed $A_{520} / A_{620}$ in generating a color intensity three-four times greater in terms of the shift of the SPR peak. We proposed that the reason for this result is the greater difference between the absorbance values at each wavelength in the spectra before and after NaCl-induced AuNP aggregation. This phenomenon can be clearly seen in the Figure S1 of Supplementary Materials, where the differences in absorbance at $720 \mathrm{~nm}$ between the red (before aggregation) and blue (after aggregation) curves are greater than the difference at $620 \mathrm{~nm}$. The relevant parameter is thus the difference between absorbances (not the absolute value); therefore, a greater difference at $720 \mathrm{~nm}$ is expected to decrease the detection limit by providing a stronger colorimetric signal. To the best of our knowledge this is the first study proposing the absorption ratio $\mathrm{A}_{520} / \mathrm{A}_{720} \mathrm{~nm}$ as a way to improve the sensitivity of the NAS.

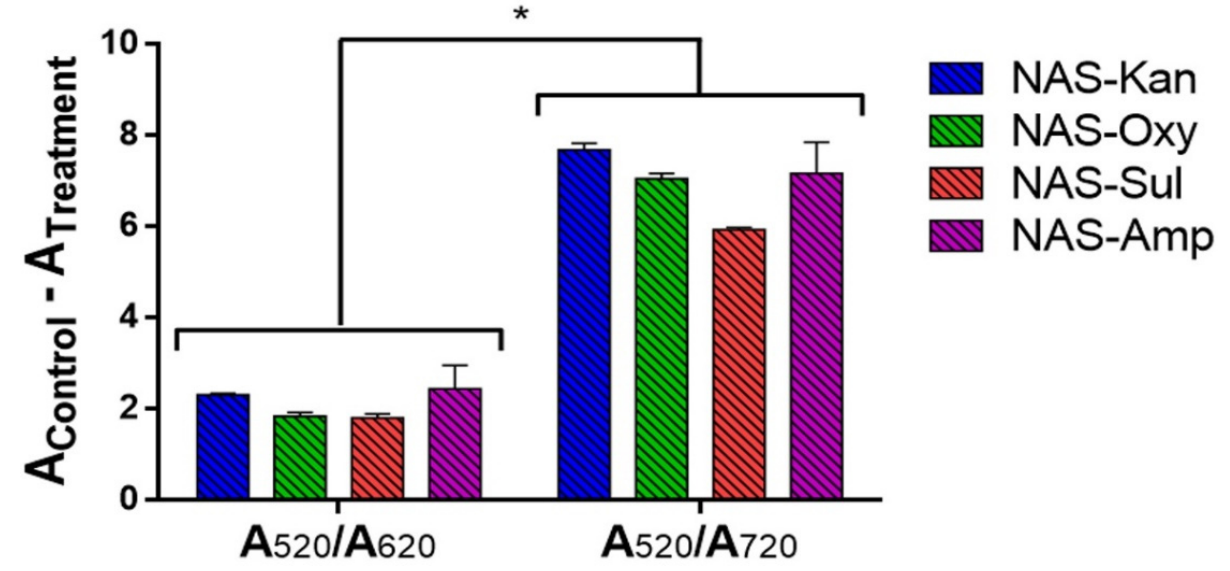

Figure 3. Comparison of the absorption ratios $A_{520} / A_{620}$ and $A_{520} / A_{720}$ from spectral variation associated with the aggregation of AuNPs as a colorimetric signal generated by the NAS in the detection of kanamycin (blue), oxytetracycline (green), sulfadimethoxine (red) and ampicillin (purple). Treatments correspond to antibiotic-containing samples at the MRL concentrations of each antibiotic, while controls include nanopure water instead of antibiotics. The absorbance readings were transformed according to Equation (1). Results were averaged from 3 to 5 independent experiments. Data were analyzed using a nonparametric Mann-Whitney U test. Asterisks denote statistically significant differences between the treatments and controls. ${ }^{*}=p<0.05$. 
Figure 4 presents the spectral variation across time resulting from the salt-induced aggregation of AuNPs for the four NAS. The curves exhibit an exponential decay, with a sharp decrease in the absorption ratio over the first 5 min followed by a slower exponential decline between 30 and $60 \mathrm{~min}$. Based on these results the incubation time with $\mathrm{NaCl}$ was established as $30 \mathrm{~min}$ prior to proceeding with spectroscopic characterization.

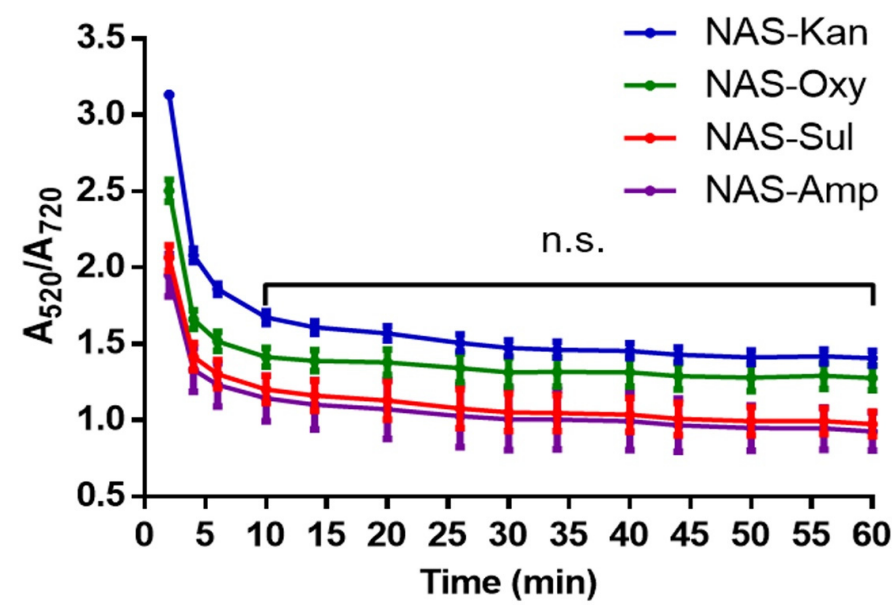

Figure 4. Kinetics of the aggregation of AuNPs in response to NAS detecting kanamycin (red), oxytetracycline (green), sulfadimethoxine (blue) and ampicillin (purple) upon the addition of $\mathrm{NaCl}$. The results were averaged from 3 independent experiments for each NAS $(n=3)$. Non-significant differences are shown as n.s. Data were analyzed using a nonparametric Mann-Whitney U test.

The previously determined parameters were employed in antibiotic detection experiments. As shown in Figure 5, the NAS allowed for the discrimination of trace-level concentrations of the antibiotics kanamycin $(0,37.5,75$ and $150 \mu \mathrm{g} / \mathrm{L})$, oxytetracycline $(0,50$, 100 and $200 \mu \mathrm{g} / \mathrm{L}$ ), sulfadimethoxine (above $12.5 \mu \mathrm{g} / \mathrm{L}$ ) and ampicillin (above $1 \mu \mathrm{g} / \mathrm{L}$ ).

A
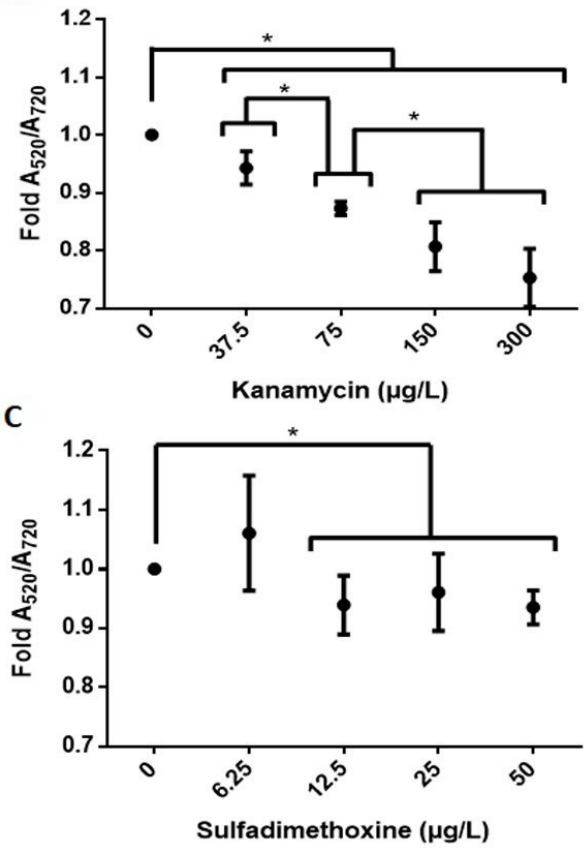

B
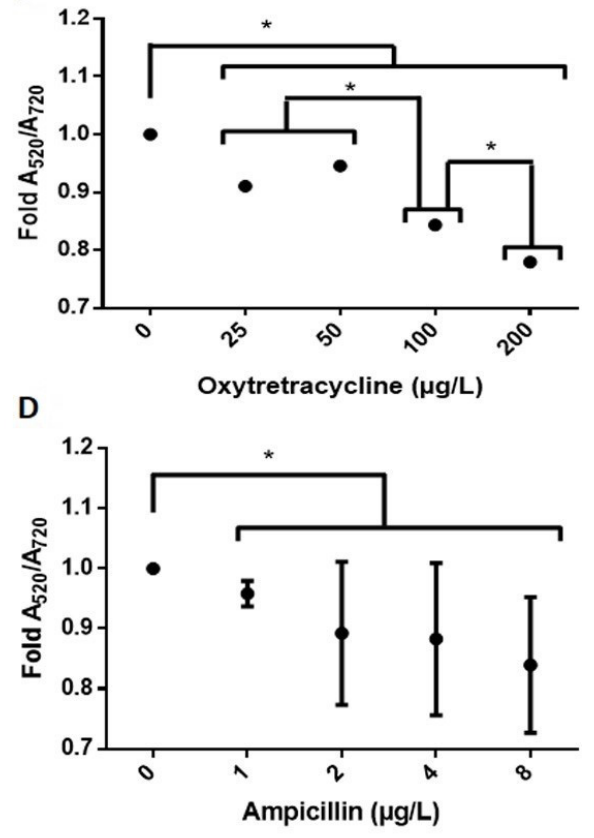

Figure 5. Colorimetric detection of the antibiotics in water for (A) kanamycin, (B) oxytetracycline, (C) sulfadimethoxine and (D) ampicillin, based on the $\mathrm{A}_{520} / \mathrm{A}_{720}$ absorption ratio. Results were averaged from three independent experiments $(n=3)$. Data were analyzed using a nonparametric Mann-Whitney $\mathrm{U}$ test. Asterisks denote statistically significant differences between the treatments and controls. ${ }^{*}=p<0.05$. 
These results suggest the need to include spectral information above $700 \mathrm{~nm}$ to better analyze the aggregation of AuNPs, in contrast with the most common approach of following the shift of the SPR band between $520 \mathrm{~nm}$ (red) and 620 or $650 \mathrm{~nm}$ (purple-blue) [37,41,42].

\subsection{Raw Milk Clarification}

The aggregation behavior of non-functionalized AuNPs in raw milk was initially determined in order to explore the activity of the NAS in this matrix. Figure S2 accounts for the absorption spectra of dispersed $(\sim 15 \mathrm{~nm})$ and aggregated nanoparticles in the raw milk, which showed no spectral change in the plasmon resonance peak (at $520 \mathrm{~nm}$ ) when incubating AuNP-containing raw milk with $\mathrm{NaCl} 0.1 \mathrm{M}$. The aggregation of AuNPs was followed through the $\mathrm{A}_{520} / \mathrm{A}_{620}$ ratio by increasing the $\mathrm{NaCl}$ concentration from 0.1 to $0.5 \mathrm{M}$. No significant differences between the control (without $\mathrm{NaCl}$ ) and treated samples (with $\mathrm{NaCl}$ ) were observed. The lack of aggregation of AuNPs in the milk suggests that the nanoparticles are strongly stabilized by electrostatic interactions with lactose or ion species, which interfere with the activity of NAS.

Two preanalytical treatments were employed for protein and fat removal from raw milk. The procedure based on the Carrez reagent produces two layers consisting of the supernatant (whey) and a precipitate of proteins and fat (Figure 6A). Instead, ethyl acetate forms three distinct layers corresponding to ethyl acetate (upper layer), a white layer of insoluble constituents (middle layer) and milk whey (bottom layer) (Figure 6B). The Carrez method outperformed in effectivity and simplicity the treatment with ethyl acetate to clarify raw milk, allowing around $98 \%$ of the protein content to be removed with the full elimination of fats (Table 3).

The Carrez method is often employed in the preanalytical processing of complex matrices. However, the absorption spectra of the four NAS in the resulting milk whey still showed no variations, accounting for a strong stabilization of the nanoparticles caused by ionic species in this solution (Figure S3). The NAS are prevented from generating a colorimetric response under these conditions, requiring further clarification steps.

A

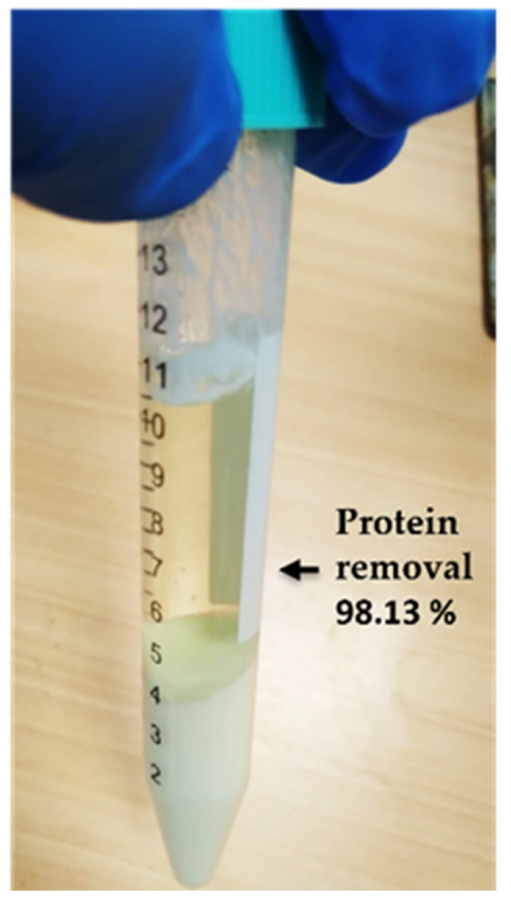

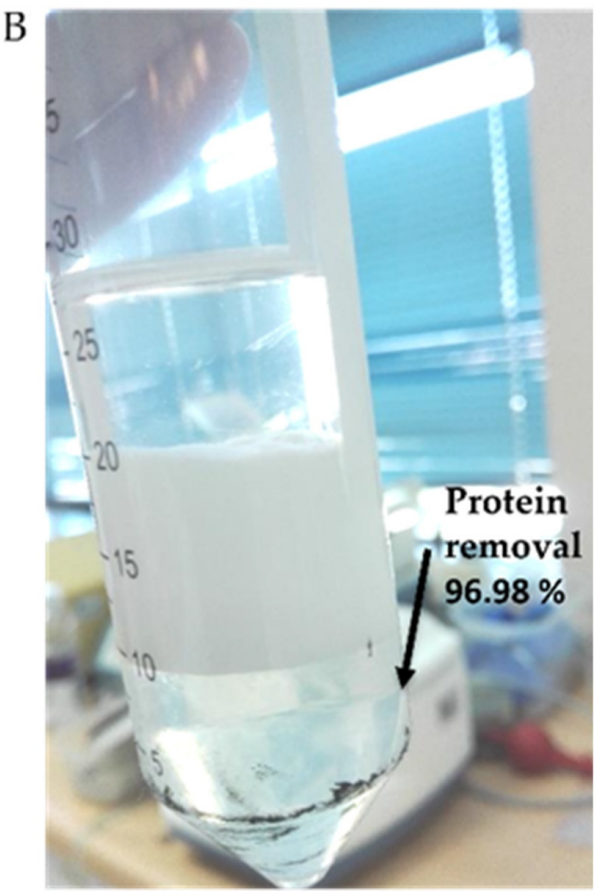

Figure 6. Phases and protein removal resulting from raw milk clarification using (A) the Carrez reagent and (B) ethyl acetate. 
Table 3. Proximate analysis of raw milk and whey obtained with the Carrez method.

\begin{tabular}{ccc}
\hline Components & Raw Milk & Milk Whey \\
\hline Lipids & $5.3 \%$ & $0.0 \%$ \\
Proteins & $3.2 \%$ & $0.2 \%$ \\
Raw fiber & $0.4 \%$ & $0.6 \%$ \\
Total carbohydrates & $4.7 \%$ & $4.5 \%$ \\
Lactose & $5.0 \%$ & $5.3 \%$ \\
Ashes & $0.7 \%$ & $1.2 \%$ \\
pH & 5.94 & 6.05 \\
\hline
\end{tabular}

\subsection{Effect of Ion and Lactose on the Aggregation of AuNPs}

In the milk serum sodium and potassium ions $\left(\mathrm{Na}^{+}\right.$and $\left.\mathrm{K}^{+}\right)$form weak ion pairs with chloride, citrate and phosphate, mainly remaining as free ions while divalent cations $\left(\mathrm{Ca}^{2+}\right.$ and $\left.\mathrm{Mg}^{2+}\right)$ are mostly complexed with citrate [52]. These cations are thus capable of interacting with negative charges of the citrate layer adsorbed onto AuNPs (citrate-capped AuNPs) and with phosphate groups from the DNA aptamers, thereby competing with electrostatic interactions that stabilize the nanoparticles and inducing their aggregation. This phenomenon occurs due to the displacement of the capping citrate layer and the consequent loss of the repulsive charges that counteract the van der Waal attractive forces between gold particles. Lactose, on the other hand, is the mayor carbohydrate component of milk and its interaction with AuNPs is also expected to influence aggregation. Given these complex interactions, synthetic milk whey (SMW) mimicking the ions and lactose composition of bovine raw milk was prepared with the aim of understanding the specific effects of these components on the activity of NAS.

Figure 7 shows that the SMW (red line) and the ionic solution (blue line) induce the aggregation of AuNPs even before the addition of $\mathrm{NaCl}$, according to the spectral shift of the plasmon resonance peak. The lactose solution (green line) prevented the salt-induced aggregation of AuNPs from taking place upon incubation both without $\mathrm{NaCl}$ (Figure 7A) and with $\mathrm{NaCl}$ (Figure 7B). This result suggests that lactose-AuNP interactions contribute to the stabilization of nanoparticles and would therefore inhibit salt-induced aggregation, a finding that is in agreement with previous works that show that this molecule is capable of interacting with metals cations such as iron [53] and calcium [54]. A recent study also reports the interaction of gold with the acetalized $\mathrm{OH}$ group of lactose [55]. Figure 7A,C point to the strong effect of milk ions on the aggregation of AuNPs as long as the aggregation of AuNPs caused by the ionic solution is similar to that induced by $\mathrm{NaCl}$ incubation, even decreasing the concentration of the ions four-fold. The activity of NAS becomes suppressed due to this effect (Figure S3).
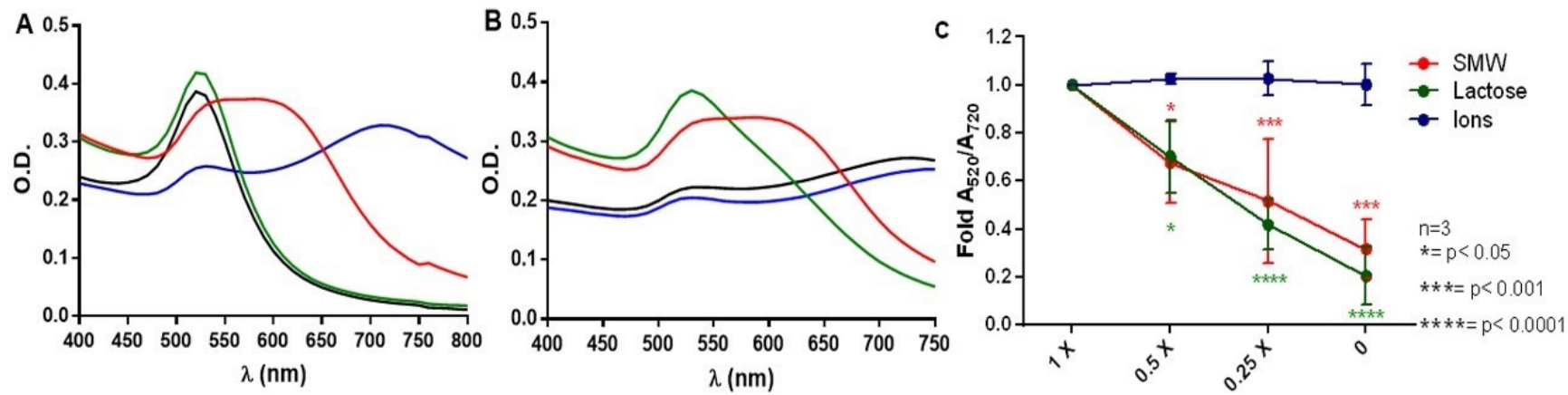

Figure 7. Spectroscopic characterization of the aggregation of AuNPs in synthetic whey (red line), lactose (green line), solution of ion species (blue line) and water (black line) during the incubation of AuNPs at (A) 10 min without the addition of $\mathrm{NaCl}$ addition and (B) $30 \mathrm{~min}$ after the addition of $\mathrm{NaCl}$ addition. (C) Effect of the solution dilution on the aggregation of AuNPs. The curves are based on the average of the results from three independent experiments $(n=3)$. Statistically significant differences compared with the controls and different treatments are indicated as ${ }^{*} p<0.05,{ }^{* * *} p<0.001$ and **** $p<0.0001$. 
The concentration of ions in the milk whey includes $132.423 \mathrm{mEq} / \mathrm{L}$ of cations (mono, $\mathrm{di}$ and trivalent) and $110.329 \mathrm{mEq} / \mathrm{L}$ of anions, where citrate and $\mathrm{PO}_{4}{ }^{3-}$ bind and chelate metallic cations in the solution (Table 2 ). Accordingly, $\approx 22.1 \mathrm{mEq} / \mathrm{L}$ of free cations are in theory involved in the aggregation of NAS. On the other hand, the aggregation of NAS induced by $\mathrm{NaCl}$ (monovalent cation) occurs at concentrations of $100 \mathrm{mEq} / \mathrm{L}$ of cations, while the aggregation of AuNPs starts at above $50 \mathrm{mEq} / \mathrm{L}$ (Figure S4). This analysis suggests that cations with a higher valence generate a stronger effect on the aggregation of AuNPs under equal conditions of normal concentration (Eq/L). Therefore, both cations and lactose need to be removed from the milk whey to make the aggregation of AuNPs possible and allow the NAS to be applied in this matrix.

\subsection{Cation Removal and Antibiotic Detection}

Figure 8 shows that both the dilution and treatment of milk whey with chelating (EDTA) and precipitating $\left(\mathrm{NaHCO}_{3}\right)$ agents allow the NAS to colorimetrically detect the corresponding antibiotics in concentrations as low as $0.25 \times$ their corresponding MRL. EDTA acts by sequestering divalent cations present in whey $\left(\mathrm{Ca}^{2+}\right.$ and $\left.\mathrm{Mg}^{2+}\right)$, while $\mathrm{NaHCO}_{3}$ precipitates $\mathrm{Ca}^{2+}\left(\right.$ as $\left.\mathrm{CaCO}_{3}\right)$ and $\mathrm{Mg}^{2+}\left(\right.$ as $\left.\mathrm{Mg}(\mathrm{OH})_{2}\right)$. The colorimetrical signal is inversely correlated with the concentration of the different antibiotics $(0-600 \mu \mathrm{g} / \mathrm{L})$, where a decrease in the signal accounts for a larger presence of antibiotics in raw milk. Therefore, preanalytical steps must be considered as a part of the protocol to eliminate interference effects of cationic species, though the specific treatment with EDTA or $\mathrm{NaHCO}_{3}$ would depend on the antibiotic.
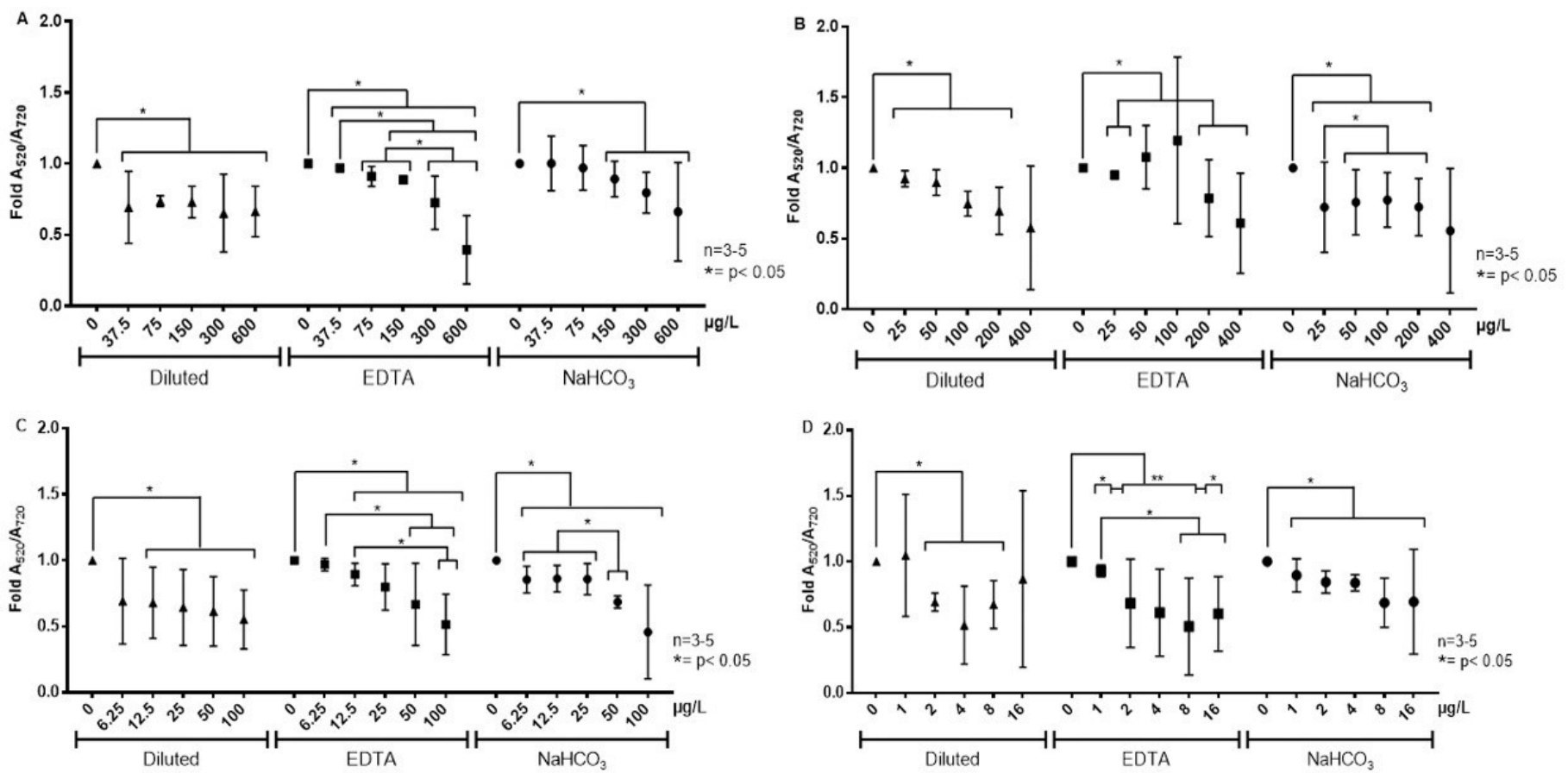

Figure 8. Colorimetric detection of antibiotics in cation-removed milk whey with NAS specific for (A) kanamycin, (B) oxytetracycline, (C) sulfadimethoxine and (D) ampicillin. The interferents were removed by dilution $(\boldsymbol{\Delta})$, EDTA treatment $(\boldsymbol{\square})$ and $\mathrm{NaHCO}_{3}$ treatment $(\bullet)$. The results were averaged from three independent experiments $(n=3)$. Statistically significant differences compared with the controls and different treatments are indicated. ${ }^{*} p<0.05$ and ${ }^{* *} p<0.01$.

As summarized in Table 4, the methods employed to remove cations from the milk whey (dilution, chelation or precipitation) enabled the NAS to perform the sensitive detection of kanamycin (from $37.5 \mu \mathrm{g} / \mathrm{L}$ ), oxytetracycline (from $25 \mu \mathrm{g} / \mathrm{L}$ ), sulfadimethoxine (from $6.25 \mu \mathrm{g} / \mathrm{L}$ ) and ampicillin (from $1 \mu \mathrm{g} / \mathrm{L}$ ) in the clarified matrix. However, some of the treatments are associated with a higher degree of data dispersion (colorimetric signal) 
and these differences were further analyzed to select the best preanalytical methodology. In the case of kanamycin, the EDTA treatment allowed a highly sensitive detection to be achieved and qualitative discrimination between concentrations lower and higher than its MRL $(150 \mu \mathrm{g} / \mathrm{L})$. By contrast, the dilution and $\mathrm{NaHCO}_{3}$ treatments only allowed for the detection of the presence of antibiotics at the MRL concentration. For oxytetracycline both the dilution with water and $\mathrm{NaHCO}_{3}$ treatments enabled sensitive detection (from 25 to $200 \mu \mathrm{g} / \mathrm{L}$ ), even though dilution was associated with less data variation and thus with a better detection performance. The $\mathrm{NaHCO}_{3}$ treatment was also suitable to perform the sensitive detection of sulfadimethoxine (from $6.25 \mu \mathrm{g} / \mathrm{L}$ ) and to discriminate concentrations under the MRL and up to two-fold the MRL $(50 \mu \mathrm{g} / \mathrm{L})$. Instead, the dilution and EDTA treatments allowed for detection (from $12.5 \mu \mathrm{g} / \mathrm{L}$ ) but without discrimination capability. Finally, the EDTA and $\mathrm{NaHCO}_{3}$ treatments were associated with the sensitive detection of ampicillin (from $1 \mu \mathrm{g} / \mathrm{L}$ ). However, EDTA outperformed $\mathrm{NaHCO}_{3}$ in discriminating among different concentrations, despite it producing a rather high data dispersion. Therefore, the methodologies developed herein provide suitable conditions to discriminate at least 0.25 times the MRLs of each antibiotic, making it possible to implement the semiquantitative detection of them in samples of contaminated raw milk.

Table 4. Selected methods for the removal of cationic interferents, which provide the minimum detection limit of antibiotic for each NAS

\begin{tabular}{ccc}
\hline Nanoaptasensor & $\begin{array}{c}\text { Best Method for } \\
\text { Interference Elimination }\end{array}$ & Detection Limit \\
\hline Kanamycin & EDTA & $37.50 \mu \mathrm{g} / \mathrm{L}(0.25 \mathrm{MRL})$ \\
Oxytetracycline & Dilution & $25.00 \mu \mathrm{g} / \mathrm{L}(0.25 \mathrm{MRL})$ \\
Sulfadimethoxine & $\mathrm{NaHCO}_{3}$ & $6.25 \mu \mathrm{g} / \mathrm{L}(0.25 \mathrm{MRL})$ \\
Ampicillin & EDTA & $1.00 \mu \mathrm{g} / \mathrm{L}(0.25 \mathrm{MRL})$ \\
\hline
\end{tabular}

In summary, the experimental strategy developed in this work involves three simple steps: (i) removal of fats and proteins with the Carrez reagents; (ii) elimination of ionic interferents by either dilution, chelation (EDTA) or precipitation $\left(\mathrm{NaHCO}_{3}\right)$, depending on the target antibiotic; and (iii) incubation with the NAS to generate the colorimetric response (Figure 9).

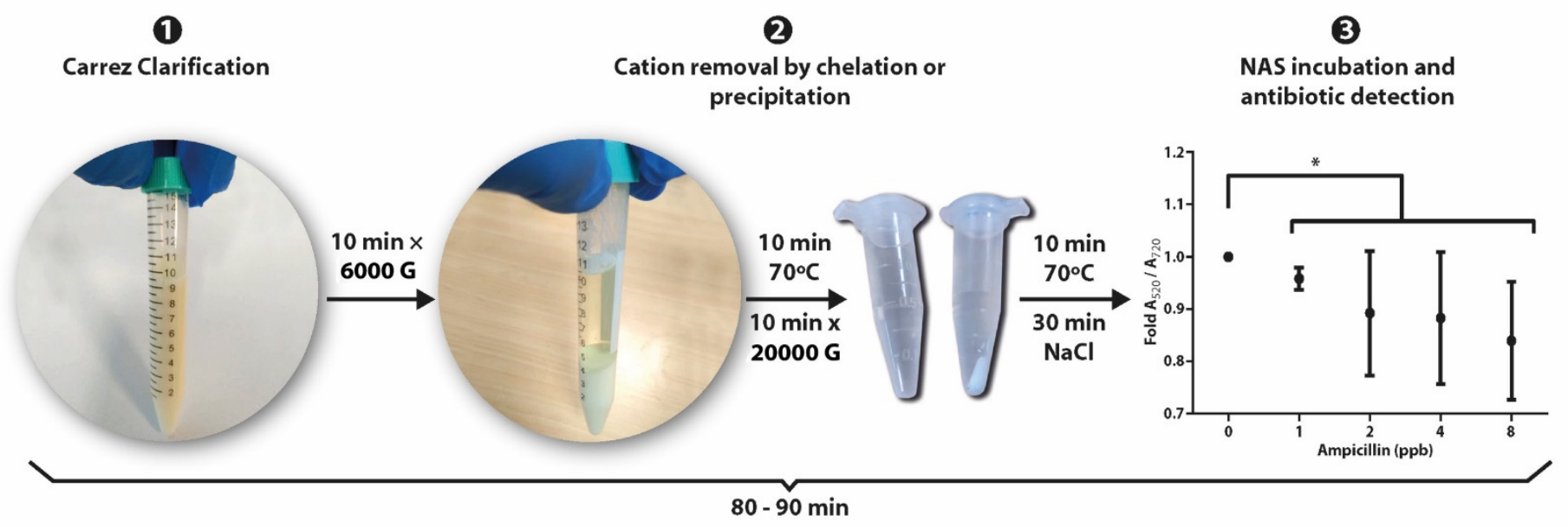

Figure 9. Preanalytical and analytical steps of the methodology developed to apply NAS technology for the detection in raw milk of kanamycin, oxytetracycline, sulfadimethoxine and ampicillin at MRL concentration levels.

Table 5 shows that the methodology developed reached low detection limits (nM range) and assay times (70 $\mathrm{min}$ ) that are comparable with similar methods, but avoided the use of organic solvents and the requirement of complex pretreatment procedures. The proposed approach allowed for the gain of knowledge on the influence of the milk matrix 
on NAS activity, focusing on the preanalytical strategy required to implement the detection of antibiotic residues in raw milk directly obtained and assayed in a dairy farm. In addition, this is the first study addressing the effect of raw milk constituents on the colorimetric response of NAS in the process of detecting antibiotics belonging to four different groups (aminoglycoside, tetracycline, sulfonamide and beta-lactam).

Table 5. Colorimetric AuNP-based aptasensors for the determination of antibiotics in milk.

\begin{tabular}{|c|c|c|c|c|c|c|c|}
\hline Milk Sample & $\begin{array}{l}\text { Antibiotic } \\
\text { Residue }\end{array}$ & $\begin{array}{c}\text { Preanalytical } \\
\text { Time }\end{array}$ & Assay Time & LOD & Range & $\begin{array}{c}\text { Pretreatment/Antibiotic } \\
\text { Addition }\end{array}$ & Ref. \\
\hline $\begin{array}{l}\text { Supermarket } \\
\text { milk }\end{array}$ & $\begin{array}{l}\text { Ampicillin } \\
\text { (AMP) }\end{array}$ & $1.5 \mathrm{~h}$ & $80 \mathrm{~min}$ & $\begin{array}{l}10 \mathrm{ng} / \mathrm{mL} \\
(28.6 \mathrm{nM})\end{array}$ & $\begin{array}{l}1-100 \mathrm{ng} / \mathrm{mL} \\
(2.86-286 \mathrm{nM})\end{array}$ & $\begin{array}{c}\text { Ethyl acetate } \\
\text { addition/centrifugation at } \\
5000 \mathrm{rpm} \text { to obtain } \\
\text { supernatant/nitrogen } \\
\text { blow-down at } 40^{\circ} \mathrm{C} / \text { pellet } \\
\text { resuspension in water (total } \\
\text { dilution: } 2 \text {-fold)/AMP } \\
\text { addition (after pretreatment). }\end{array}$ & [43] \\
\hline N.S. & $\begin{array}{l}\text { Tetracycline } \\
\quad(\mathrm{TET})\end{array}$ & N.S. & $25 \min$ & $45.8 \mathrm{nM}$ & $10-400 \mathrm{nM}$ & $\begin{array}{c}\text { Milk dilution with water } \\
\text { (1:5)/acetic acid } \\
\text { addition/centrifugation (total } \\
\text { dilution: 5-fold)/TET } \\
\text { addition (protocol details } \\
\text { unspecified). }\end{array}$ & {$[56]$} \\
\hline Milk powder & $\begin{array}{l}\text { Tetracycline } \\
\text { (TET) }\end{array}$ & N.S. & $60 \mathrm{~min}$ & $122 \mathrm{nM}$ & $10-500 \mathrm{nM}$ & $\begin{array}{l}\text { Acetic acid addi- } \\
\text { tion/centrifugation/TET } \\
\text { addition (protocol details } \\
\text { unspecified). }\end{array}$ & {$[32]$} \\
\hline N.S. & $\begin{array}{l}\text { Kanamycin } \\
\text { (KAN) }\end{array}$ & $35 \min$ & $100 \mathrm{~min}$ & $1 \mathrm{nM}$ & $\begin{array}{c}1-8 \mathrm{nM} \\
100-500 \mathrm{nM}\end{array}$ & $\begin{array}{c}\text { KAN addition (before } \\
\text { pretreatment)/acetic acid } \\
\text { addition/incubation at } \\
45^{\circ} \mathrm{C} / \text { centrifugation at } \\
10,000 \mathrm{rpm} / \text { filtration } \\
0.22 \mu \mathrm{m} / \mathrm{pH} \text { adjustment } \\
\text { (total dilution unspecified). }\end{array}$ & [31] \\
\hline N.S. & $\begin{array}{l}\text { Streptomycin } \\
\text { (STR) }\end{array}$ & N.A. & $70 \mathrm{~min}$ & $73.1 \mathrm{nM}$ & 30-1030 nM & $\begin{array}{l}\text { Milk dilution with water } \\
\text { (total dilution: } 50 \text {-fold)/STR } \\
\text { addition (after pretreatment). }\end{array}$ & [34] \\
\hline $\begin{array}{l}\text { Supermarket } \\
\text { milk }\end{array}$ & $\begin{array}{l}\text { Streptomycin } \\
\text { (STR) }\end{array}$ & $30 \mathrm{~min}$ & $60 \mathrm{~min}$ & $86 \mathrm{nM}$ & $100-500 \mathrm{nM}$ & $\begin{array}{l}\text { Milk dilution with water } \\
\text { (total dilution: } 5 \text {-fold)/STR } \\
\text { addition (after dilution)/ } \\
\text { EDTA and trifluoracetic acid } \\
\text { addition/centrifugation at } \\
6000 \mathrm{rpm} / \text { supernatant } \\
\text { collection. }\end{array}$ & [35] \\
\hline $\begin{array}{l}\text { Raw milk from } \\
\text { a dairy farm }\end{array}$ & $\begin{array}{l}\text { Ampicillin } \\
\text { Oxytetracycline } \\
\text { Sulfadimethoxine } \\
\text { Kanamycin }\end{array}$ & $40 \mathrm{~min}$ & $30 \mathrm{~min}$ & $\begin{array}{l}1 \mu \mathrm{g} / \mathrm{L} \\
(2.9 \mathrm{nM}) \\
25 \mu \mathrm{g} / \mathrm{L} \\
(54.3 \mathrm{nM}) \\
6.25 \mu \mathrm{g} / \mathrm{L} \\
(20.9 \mathrm{nM}) \\
37.5 \mu \mathrm{g} / \mathrm{L} \\
(77.4 \mathrm{nM})\end{array}$ & $\begin{array}{c}1-16 \mu \mathrm{g} / \mathrm{L} \\
(2.9-46.4 \mathrm{nM}) \\
25-200 \mu \mathrm{g} / \mathrm{L} \\
(54.3-434.4 \mathrm{nM}) \\
6.25-100 \mu \mathrm{g} / \mathrm{L} \\
(20.9-334.4 \mathrm{nM}) \\
37.5-600 \mu \mathrm{g} / \mathrm{L} \\
(77.4-1238.4 \mathrm{nM})\end{array}$ & $\begin{array}{c}\text { Antibiotic addition (before } \\
\text { pretreatment)/Carrez } \\
\text { reagents/centrifugation at } \\
1000 \mathrm{rpm} / \text { dilution, } \\
\mathrm{NaHCO}_{3} \text { or EDTA } \\
\text { treatments/centrifugation at } \\
1000 \mathrm{rpm} / \text { supernatant } \\
\text { collection (total dilution: } \\
1.16 \text {-fold). }\end{array}$ & $\begin{array}{l}\text { This } \\
\text { study }\end{array}$ \\
\hline
\end{tabular}

N.S. = Details not specified by the authors. N.A. = Not applicable.

In contrast to our approach, previous works report the determination of antibiotics on processed (commercial) milk, which is typically subjected to treatments involving the use of chemical agents such as ethyl acetate [43], trichloroacetic acid [31,33] or trifluoracetic acid [35], followed by centrifugation/resuspension. In some cases, final steps involve the adjustment of $\mathrm{pH}$ or the removal of solvents by nitrogen blow-down [57]. Milk dilution has also been reported elsewhere as a simple clarification procedure to deal with matrix complexity by using dilution factors ranging from 5-fold [35] to 50-fold [34]. However, in these works milk samples are typically spiked with antibiotics after dilution. 
A realistic condition to apply NAS technology must consider the analyte already present in the sample of raw milk, because dilution could lower its concentration below the detection limit of the method. However, with the exception of Zhou et al. [31] the approach followed in the rest of the works consists of contaminating the milk after and not before the clarification step (Table 5). This is the reason why our work focuses on antibiotic-spiked raw milk samples, which were employed as the starting point from which to investigate a preanalytical strategy and analytical techniques necessary to advance NAS technology toward its application for real samples obtained in dairy farms. Table 5 highlights that this is the first study addressing this problem in raw milk, while other works have focused on milk powder [32], supermarket milk [35,43] or non-specified information [31,34,56]. Finally, a number of approaches have been proposed to generate and scale-up, at low costs, the production of AuNPs, as well as for the recovery of gold from laboratory wastes [58,59], which together contribute to the economic viability of this technology at an industrial level.

\section{Conclusions}

The contamination of raw milk with antibiotic residues is an issue of worldwide concern due to its impacts on the dairy industry and human health. The application of NAS for the detection of antibiotics in bovine raw milk involves preanalytical and analytical challenges related with the chemical complexity of this matrix. In this context, the bioconjugation of AuNPs with thiolated ssDNA aptamers provided suitable experimental conditions with which to apply NAS for the colorimetric detection of antibiotics in raw milk. For the first time a methodology was proposed to enable the highly sensitive colorimetric detection of antibiotics belonging to four different groups, namely kanamycin (aminoglycosides), oxytetracycline (tetracyclines), sulfadimethoxine (sulfonamides) and ampicillin (beta-lactams), using a straightforward preanalytical process. The method developed herein consists of a clarification treatment with Carrez reagents, followed by the removal of cations from milk whey through dilution, chelation (EDTA) or precipitation $\left(\mathrm{NaHCO}_{3}\right)$. In all cases the methodology allowed for the semiquantitative detection of the colorimetric signals generated by the NAS at concentrations as low as 0.25 -fold the MRL of the antibiotics. However, the specific treatment to address ionic interference (dilution/chelation/precipitation) depends on the particular antibiotic to be determined in the raw milk. Furthermore, the results proved that analyzing the spectral shift at $720 \mathrm{~nm}$ $\left(\mathrm{A}_{520} / \mathrm{A}_{720}\right)$ improved the analytical performance of the NAS in comparison with the typical absorption ratio $\left(\mathrm{A}_{520} / \mathrm{A}_{620}\right)$. Overall, this methodology combines simplicity and sensitivity for the four antibiotics, holding the potential to be applied for semiquantitative analyses of antibiotic residues in raw milk obtained directly from dairy farms.

Supplementary Materials: The following are available online at https: / www.mdpi.com/article/ 10.3390/s22031281/s1, Figure S1: Spectral variation associated with the aggregation of AuNPs of the NAS, Figure S2: Aggregation of AuNPs in raw milk, Figure S3: Detection of antibiotics in milk whey using the NAS, Figure S4: Aggregation of AuNPs versus NAS in water, Table S1: Molar ratio between AuNPs-aptamers and AuNPs-aptamers bases.

Author Contributions: Conceptualization, P.O., V.D.-G. and P.C.; methodology, V.D.-G., B.C.-T. and C.R.; formal analysis, P.O., V.D.-G., P.C. and B.C.-T.; investigation, all authors; data curation, V.D.-G. and B.C.-T.; writing-original draft preparation, V.D.-G. and P.O.; writing-review and editing, P.O., V.D.-G., B.C.-T. and P.C.; supervision, P.O. and V.D.-G.; project administration, P.O.; funding acquisition, all authors. All authors have read and agreed to the published version of the manuscript.

Funding: This research was funded by the National Agency for Research and Development (ANID) of Chile, through its programs Convocatoria Nacional Subvención a la Instalación en la Academia (grant number PAI77180078) and Fondecyt Posdoctorado (grant number 3190734).

Institutional Review Board Statement: Not applicable.

Informed Consent Statement: Not applicable. 
Data Availability Statement: The data presented in this study are available on request from the corresponding author. The data are not publicly available due to privacy restrictions.

Acknowledgments: We thank the Agriculture and Livestock Service of Chile (SAG) for valuable discussions and orientations.

Conflicts of Interest: The authors declare no conflict of interest.

\section{References}

1. Haug, A.; Høstmark, A.T.; Harstad, O.M. Bovine Milk in Human Nutrition-A Review. Lipids Health Dis. 2007, 6, 25. [CrossRef] [PubMed]

2. USDA Foreign Agricultural Service. Dairy: World Markets and Trade. Washington, DC, USA. Available online: https://Apps. Fas.Usda.Gov/Psdonline/Circulars/Dairy.Pdf (accessed on 13 September 2021).

3. Fusco, V.; Chieffi, D.; Fanelli, F.; Logrieco, A.F.; Cho, G.-S.; Kabisch, J.; Böhnlein, C.; Franz, C.M.A.P. Microbial Quality and Safety of Milk and Milk Products in the 21st Century. Compr. Rev. Food Sci. Food Saf. 2020, 19, 2013-2049. [CrossRef] [PubMed]

4. Boeckel, T.P.V.; Brower, C.; Gilbert, M.; Grenfell, B.T.; Levin, S.A.; Robinson, T.P.; Teillant, A.; Laxminarayan, R. Global Trends in Antimicrobial Use in Food Animals. PNAS 2015, 112, 5649-5654. [CrossRef] [PubMed]

5. Hao, H.; Cheng, G.; Iqbal, Z.; Ai, X.; Hussain, H.I.; Huang, L.; Dai, M.; Wang, Y.; Liu, Z.; Yuan, Z. Benefits and Risks of Antimicrobial Use in Food-Producing Animals. Front. Microbiol. 2014, 5, 288. [CrossRef]

6. Sharma, C.; Rokana, N.; Chandra, M.; Singh, B.P.; Gulhane, R.D.; Gill, J.P.S.; Ray, P.; Puniya, A.K.; Panwar, H. Antimicrobial Resistance: Its Surveillance, Impact, and Alternative Management Strategies in Dairy Animals. Front. Vet. Sci. $2018,4,237$. [CrossRef]

7. Limmathurotsakul, D.; Dunachie, S.; Fukuda, K.; Feasey, N.A.; Okeke, I.N.; Holmes, A.H.; Moore, C.E.; Dolecek, C.; van Doorn, H.R.; Shetty, N.; et al. Improving the Estimation of the Global Burden of Antimicrobial Resistant Infections. Lancet Infect. Dis. 2019, 19, e392-e398. [CrossRef]

8. O'Neill, J. Tackling Drug-Resistant Infections Globally: Final Report and Recommendations. HM Government and Welcome Trust: UK. 2016. Available online: https:/ / Amr-Review.Org/Sites/Default/Files/160518_Final\%20paper_with\%20cover.Pdf. (accessed on 18 October 2021).

9. Chiesa, L.M.; DeCastelli, L.; Nobile, M.; Martucci, F.; Mosconi, G.; Fontana, M.; Castrica, M.; Arioli, F.; Panseri, S. Analysis of Antibiotic Residues in Raw Bovine Milk and Their Impact toward Food Safety and on Milk Starter Cultures in Cheese-Making Process. LWT 2020, 131, 109783. [CrossRef]

10. Commission Regulation (EU) No 37/2010 of 22 December 2009 on Pharmacologically Active Substances and Their Classification Regarding Maximum Residue Limits in Foodstuffs of Animal Origin. Official Journal of the European Union. 2010 L15: 1-72. Available online: https:/ /Ec.Europa.Eu/Health/Sites/Default/Files/Files/Eudralex/Vol-5/Reg_2010_37/Reg_2010_37_en.Pdf (accessed on 18 October 2021).

11. MINSAL Subsecretaría de Salud Pública. Resolución 1560 Exenta Fija Límites Máximos de Residuos de Medicamentos Veterinarios En Alimentos Destinados al Consumo Humano. Santiago, Chile. Available online: https://www.Bcn.Cl/Leychile/Navegar? IdNorma $=1135977$ (accessed on 18 October 2021).

12. Gaudin, V. The Growing Interest in Development of Innovative Optical Aptasensors for the Detection of Antimicrobial Residues in Food Products. Biosensors 2020, 10, 21. [CrossRef]

13. Somwanshi, S.; Somvanshi, S.; Kharat, P. Nanocatalyst: A Brief Review on Synthesis to Applications. J. Phys. Conf. Ser. 2020, 1644, 012046. [CrossRef]

14. Jain, K.; Patel, A.S.; Pardhi, V.P.; Flora, S.J.S. Nanotechnology in Wastewater Management: A New Paradigm Towards Wastewater Treatment. Molecules 2021, 26, 1797. [CrossRef]

15. McClements, D. Nanotechnology Approaches for Improving the Healthiness and Sustainability of the Modern Food Supply. ACS Omega 2020, 5, 29623-29630. [CrossRef] [PubMed]

16. Zuliani, A.; Ranjan, P.; Luque, R.; Van der Eycken, E.V. Heterogeneously Catalyzed Synthesis of Imidazolones via Cycloisomerizations of Propargylic Ureas Using Ag and Au/Al SBA-15 Systems. ACS Sustain. Chem. Eng. 2019, 7, $5568-5575$. [CrossRef]

17. Moram, S.S.B.; Shaik, A.K.; Byram, C.; Hamad, S.; Soma, V.R. Instantaneous Trace Detection of Nitro-Explosives and Mixtures with Nanotextured Silicon Decorated with Ag-Au Alloy Nanoparticles Using the SERS Technique. Anal. Chim. Acta 2020, 1101, 157-168. [CrossRef] [PubMed]

18. Srivastava, A.K.; Dev, A.; Karmakar, S. Nanosensors and Nanobiosensors in Food and Agriculture. Environ. Chem. Lett. 2018, 16, 161-182. [CrossRef]

19. Prajapati, S.; Padhan, B.; Amulyasai, B.; Sarkar, A. Chapter 11-Nanotechnology-Based Sensors. In Biopolymer-Based Formulations; Pal, K., Banerjee, I., Sarkar, P., Kim, D., Deng, W.-P., Dubey, N.K., Majumder, K., Eds.; Elsevier: Amsterdam, The Netherlands, 2020; pp. 237-262. ISBN 978-0-12-816897-4. [CrossRef]

20. Díaz-García, V.; Retamal-Morales, G. Aptamer and Riboswitches: A Novel Tool for the Need of New Antimicrobial Active Compounds. In Antibiotic Materials in Healthcare; Kokkarachedu, V., Kanikireddy, V., Sadiku, R., Eds.; Academic Press: Cambridge, MA, USA, 2020; pp. 231-247. [CrossRef] 
21. Hu, X.; Chang, K.; Wang, S.; Sun, X.; Hu, J.; Jiang, M. Aptamer-Functionalized AuNPs for the High-Sensitivity Colorimetric Detection of Melamine in Milk Samples. PLoS ONE 2018, 13, e0201626. [CrossRef]

22. Bai, W.; Zhu, C.; Liu, J.; Yan, M.; Yang, S.; Chen, A. Gold Nanoparticle-Based Colorimetric Aptasensor for Rapid Detection of Six Organophosphorous Pesticides. Environ. Toxicol. Chem. 2015, 34, 2244-2249. [CrossRef]

23. Yin, X.; Wang, S.; Liu, X.; He, C.; Tang, Y.; Li, Q.; Liu, J.; Su, H.; Tan, T.; Dong, Y. Aptamer-Based Colorimetric Biosensing of Ochratoxin A in Fortified White Grape Wine Sample Using Unmodified Gold Nanoparticles. Anal. Sci. 2017, 33, 659-664. [CrossRef]

24. Priyadarshini, E.; Pradhan, N. Gold Nanoparticles as Efficient Sensors in Colorimetric Detection of Toxic Metal Ions: A Review. Sens. Actuators B Chem. 2017, 238, 888-902. [CrossRef]

25. Liu, G.; Lu, M.; Huang, X.; Li, T.; Xu, D. Application of Gold-Nanoparticle Colorimetric Sensing to Rapid Food Safety Screening. Sensors 2018, 18, 4166. [CrossRef]

26. Zahra, Q.; Luo, Z.; Ali, R.; Khan, M.I.; Li, F.; Qiu, B. Advances in Gold Nanoparticles-Based Colorimetric Aptasensors for the Detection of Antibiotics: An Overview of the Past Decade. Nanomaterials 2021, 11, 840. [CrossRef]

27. Zhang, F.; Liu, J. Label-Free Colorimetric Biosensors Based on Aptamers and Gold Nanoparticles: A Critical Review. Anal. Sens. 2021, 1, 30-43. [CrossRef]

28. Amendola, V.; Pilot, R.; Frasconi, M.; Maragò, O.M.; Iatì, M.A. Surface Plasmon Resonance in Gold Nanoparticles: A Review. J. Phys. Condens. Matter 2017, 29, 203002. [CrossRef]

29. Yan, S.; Foroughi, M.; Safaei, M.; Jahani, S.; Ebrahimpour, N.; Borhani, F.; Zade, N.; Aramesh-Boroujeni, Z.; Foong, L. A review: Recent advances in ultrasensitive and highly specific recognition aptasensors with various detection strategies. Int. J. Biol. Macrom. 2020, 155, 184-207. [CrossRef]

30. Andrew, S.M. Effect of Fat and Protein Content of Milk from Individual Cows on the Specificity Rates of Antibiotic Residue Screening Tests. J. Dairy Sci. 2000, 83, 2992-2997. [CrossRef]

31. Zhou, N.; Zhang, J.; Tian, Y. Aptamer-Based Spectrophotometric Detection of Kanamycin in Milk. Anal. Methods 2014, 6, 1569-1574. [CrossRef]

32. He, L.; Luo, Y.; Zhi, W.; Wu, Y.; Zhou, P.; He, L.; Luo, Y.; Zhi, W.; Wu, Y.; Zhou, P. A Colorimetric Aptamer Biosensor Based on Gold Nanoparticles for the Ultrasensitive and Specific Detection of Tetracycline in Milk. Aust. J. Chem. 2013, 66, 485-490. [CrossRef]

33. Kim, C.-H.; Lee, L.-P.; Min, J.-R.; Lim, M.-W.; Jeong, S.-H. An Indirect Competitive Assay-Based Aptasensor for Detection of Oxytetracycline in Milk. Biosens. Bioelectron. 2014, 51, 426-430. [CrossRef] [PubMed]

34. Emrani, A.S.; Danesh, N.M.; Lavaee, P.; Ramezani, M.; Abnous, K.; Taghdisi, S.M. Colorimetric and Fluorescence Quenching Aptasensors for Detection of Streptomycin in Blood Serum and Milk Based on Double-Stranded DNA and Gold Nanoparticles. Food Chem. 2016, 190, 115-121. [CrossRef]

35. Zhao, J.; Wu, Y.; Tao, H.; Chen, H.; Yang, W.; Qiu, S. Colorimetric Detection of Streptomycin in Milk Based on PeroxidaseMimicking Catalytic Activity of Gold Nanoparticles. RSC Adv. 2017, 7, 38471-38478. [CrossRef]

36. Adami, A.; Mortari, A.; Morganti, E.; Lorenzelli, L. Microfluidic Sample Preparation Methods for the Analysis of Milk Contaminants. J. Sens. 2015, 2016, e2385267. [CrossRef]

37. Contreras-Trigo, B.; Díaz-García, V.; Guzmán-Gutierrez, E.; Sanhueza, I.; Coelho, P.; Godoy, S.E.; Torres, S.; Oyarzún, P. Slight pH Fluctuations in the Gold Nanoparticle Synthesis Process Influence the Performance of the Citrate Reduction Method. Sensors 2018, 18, 2246. [CrossRef]

38. Maye, M.M.; Han, L.; Kariuki, N.N.; Ly, N.K.; Chan, W.-B.; Luo, J.; Zhong, C.-J. Gold and Alloy Nanoparticles in Solution and Thin Film Assembly: Spectrophotometric Determination of Molar Absorptivity. Anal. Chim. Acta 2003, 496, 17-27. [CrossRef]

39. Hill, H.D.; Mirkin, C.A. The Bio-Barcode Assay for the Detection of Protein and Nucleic Acid Targets Using DTT-Induced Ligand Exchange. Nat. Protoc. 2006, 1, 324-336. [CrossRef] [PubMed]

40. Song, K.-M.; Cho, M.; Jo, H.; Min, K.; Jeon, S.H.; Kim, T.; Han, M.S.; Ku, J.K.; Ban, C. Gold Nanoparticle-Based Colorimetric Detection of Kanamycin Using a DNA Aptamer. Anal. Biochem. 2011, 415, 175-181. [CrossRef] [PubMed]

41. Kim, Y.S.; Kim, J.H.; Kim, I.A.; Lee, S.J.; Jurng, J.; Gu, M.B. A Novel Colorimetric Aptasensor Using Gold Nanoparticle for a Highly Sensitive and Specific Detection of Oxytetracycline. Biosens. Bioelectron. 2010, 26, 1644-1649. [CrossRef]

42. Chen, A.; Jiang, X.; Zhang, W.; Chen, G.; Zhao, Y.; Tunio, T.M.; Liu, J.; Lv, Z.; Li, C.; Yang, S. High Sensitive Rapid Visual Detection of Sulfadimethoxine by Label-Free Aptasensor. Biosens. Bioelectron. 2013, 42, 419-425. [CrossRef]

43. Song, K.-M.; Jeong, E.; Jeon, W.; Cho, M.; Ban, C. Aptasensor for Ampicillin Using Gold Nanoparticle Based Dual FluorescenceColorimetric Methods. Anal. Bioanal. Chem. 2012, 402, 2153-2161. [CrossRef]

44. Horwitz, W.; Latimer, G.W. Official Methods of Analysis of AOAC International; AOAC International: Gaithersburg, MA, USA, 2005.

45. Xue, Y.; Li, X.; Li, H.; Zhang, W. Quantifying Thiol-Gold Interactions towards the Efficient Strength Control. Nat. Commun. 2014, 5, 4348. [CrossRef]

46. Adeel, M.; Rahman, M.; Lee, J.-J. Label-Free Aptasensor for the Detection of Cardiac Biomarker Myoglobin Based on Gold Nanoparticles Decorated Boron Nitride Nanosheets. Biosens. Bioelectron. 2019, 126, 143-150. [CrossRef]

47. Peng, Y.; Li, L.; Mu, X.; Guo, L. Aptamer-Gold Nanoparticle-Based Colorimetric Assay for the Sensitive Detection of Thrombin. Sens. Actuators B Chem. 2013, 177, 818-825. [CrossRef] 
48. Azzam EM, S.; El-Farargy AF, M.; Hegazy, M.A.; Abd El-Aal, A.A. Detection of Heavy Metal Ions Using Synthesized Amino Thiol Surfactants Assembled on Gold Nanoparticles. J. Disp. Sci. Technol. 2014, 35, 175-184. [CrossRef]

49. Li, H.; Rothberg, L. Colorimetric Detection of DNA Sequences Based on Electrostatic Interactions with Unmodified Gold Nanoparticles. PNAS 2004, 101, 14036-14039. [CrossRef] [PubMed]

50. Ma, Q.; Wang, Y.; Jia, J.; Xiang, Y. Colorimetric aptasensors for determination of tobramycin in milk and chicken eggs based on DNA and gold nanoparticles. Food Chem. 2018, 30, 98-103. [CrossRef] [PubMed]

51. Gutiérrez, P.; Godoy, S.E.; Torres, S.; Oyarzún, P.; Sanhueza, I.; Díaz-García, V.; Contreras-Trigo, B.; Coelho, P. Improved Antibiotic Detection in Raw Milk Using Machine Learning Tools over the Absorption Spectra of a Problem-Specific Nanobiosensor. Sensors 2020, 20, 4552. [CrossRef]

52. Holt, C. The Milk Salts and Their Interaction with Casein. In Advanced Dairy Chemistry: Lactose, Water, Salts and Vitamins; Fox, P.F., Ed.; Springer: Boston, MA, USA, 1997; Volume 3, pp. 233-256. [CrossRef]

53. Bachran, K.; Bernhard, R.A. Interaction of Iron(II) with Lactose. J. Agric. Food Chem. 1980, 28, 536-540. [CrossRef]

54. Reynolds, A.J.; Haines, A.H.; Russell, D.A. Gold Glyconanoparticles for Mimics and Measurement of Metal Ion-Mediated Carbohydrate-Carbohydrate Interactions. Langmuir 2006, 22, 1156-1163. [CrossRef]

55. Ho, T.T.-T.; Dang, C.-H.; Huynh, T.K.-C.; Hoang, T.K.-D.; Nguyen, T.-D. In Situ Synthesis of Gold Nanoparticles on Novel Nanocomposite Lactose/Alginate: Recyclable Catalysis and Colorimetric Detection of Fe(III). Carbohydr. Polym. 2021, $251,116998$. [CrossRef]

56. He, L.; Luo, Y.; Zhi, W.; Zhou, P. Colorimetric Sensing of Tetracyclines in Milk Based on the Assembly of Cationic Conjugated Polymer-Aggregated Gold Nanoparticles. Food Anal. Methods 2013, 6, 1704-1711. [CrossRef]

57. Chen, M.; Gan, N.; Zhou, Y.; Li, T.; Xu, Q.; Cao, Y.; Chen, Y. A novel aptamer- metal ions- nanoscale MOF based electrochemical biocodes for multiple antibiotics detection and signal amplification. Sens. Actuators B Chem. 2017, 242, 1201-1209. [CrossRef]

58. Giannone, G.; Santi, M.; Ermini, M.L.; Cassano, D.; Voliani, V. A Cost-Effective Approach for Non-Persistent Gold NanoArchitectures Production. Nanomaterials 2020, 10, 1600. [CrossRef]

59. Gan, P.P.; Ng, S.H.; Huang, Y.; Li, S.F. Green synthesis of gold nanoparticles using palm oil mill effluent (POME): A low-cost and eco-friendly viable approach. Bioresour. Technol. 2012, 113, 132-135. [CrossRef] [PubMed] 